\title{
Quality Improvement Indicators in Inflammatory Bowel Disease
}

\author{
Ted Walker MD and George P Christophi MD, PhD* \\ Inflammatory Bowel Disease Center, Washington University School of Medicine, USA
}

Submission: April 26, 2017; Published: May 26, 2017

"Corresponding author: George P Christophi, MD, PhD, Division of Gastroenterology, Washington University School of Medicine, St. Louis, MO, 660 S. Euclid Ave., Box 8121, St. Louis, MO 63110, USA, Tel: 314-273-1947. Email: christophig@wustl.edu

\begin{abstract}
Inflammatory bowel disease (IBD) is a chronic immune-mediated disease that provides a unique opportunity for improvement in the quality of clinical care. There is high variation in the care received by IBD patients and this variation in care is often used as a surrogate for poor quality of care delivered. The American Gastroenterological Association (AGA) established a performance measurement set aimed at increasing patient safety, improving treatment, decreasing steroid use and decreasing complications related to treatment. In parallel, the Crohn's and Colitis Foundation of America (CCFA) developed a set of process and outcome quality indicators for IBD. By incorporating these quality indicators into daily practice, the goal is to improve clinical outcomes, quality of life, and decrease healthcare costs. This review, discusses the quality indicators offered by AGA and CCFA and examines both obstacles and avenues to facilitate adherence to these quality measures.
\end{abstract}

Keywords: Ulcerative colitis; Crohn's disease; Quality improvement indicators; Preventive health measures

\section{Introduction}

Inflammatory bowel disease (IBD) classified as Crohn's disease (CD) or ulcerative colitis (UC) is a chronic immunemediated disease of the gastrointestinal tract that affects more than 1.6 million Americans [1]. IBD pathogenesis involves an exaggerated immune response against gut microbiota in the presence of genetic defects, leading to exaggerated self-injurious inflammatory responses and impaired intestinal wound healing. Genome-wide association studies have identified numerous IBD susceptibility genes, however it has not contributed to direct advancements in clinical management. The mainstay therapy for IBD involves anti-inflammatory immunosuppression dictated by the severity and location of disease. Moderate-to-severe disease is typically treated with immunosuppressive medications such as azathioprine, anti-TNF, and more recently, anti-integrin agents [2]. Thiopurine therapy is associated with a rare increased risk of myelosuppression, lymphoma, and non-melanoma skin cancer; biologic treatment is associated with increased infection risk necessitating the need for close monitoring and preventive care. Oral corticosteroids are limited to treating acute flares, have limited efficacy in maintaining remission, and are associated with harmful side-effects such as osteoporosis, adrenal insufficiency, and diabetes [3].
In addition to intestinal inflammation, the prevalence of IBD increases the risk of invasive infections, osteoporosis, and thromboembolic events independent of medications, underscoring the need for monitoring and treating systemic clinical adverse outcomes in IBD [4-6]. Importantly, IBD confers a significant increased risk of developing colorectal cancer requiring frequent and augmented screening6.Patients with IBS have extensive morbidity and extensive reduction in life quality [7]. The presence of IBD estimated cost in the United States is as high as \%2.6 billion annually. [8].

The chronic nature of this illness provides a unique opportunity for improvement in the quality of care delivered. Studies have shown that there is high variation in the care received by IBD patients [9]. Variation in care is often used as a surrogate for poor quality of care delivered. Recent studies have suggested that IBD patients do not receive preventive services at the same rate as general medical patients [10]. One study reported that up to $11 \%$ of patients may even receive care that is not recommended based on practice guidelines and could even potentially be harmful [11].

For example, recommendations suggest to screen IBD patients for osteoporosis every 5 years. 4 In fact, in clinical 
practice, screening and treatment for osteoporosis was highly variable; in clinical centers that care for a high volume IBD patients, $52 \%$ of patients were screened compared to $16 \%$ of patients screened in centers with low volume IBD patients [12]. urthermore, in some studies only $25 \%$ of patients with ulcerative colitis received adequate colorectal cancer screening [13]. These findings highlight existing gaps in IBD care and underscore the importance of implementing quality improvement measures in IBD.

In 2011, the American Gastroenterological Association (AGA) established a performance measurement set aimed at increasing patient safety, improving treatment, decreasing steroid use and decreasing complications related to treatment (Table 1) [14]. In parallel, the Crohn's and Colitis Foundation of America (CCFA) developed a set of process and outcome quality indicators (Qis) for IBD (Table 2) [15]. It is important to note that these Qis are not meant to reflect the ideal care for IBD patients, but rather are meant to be a minimum acceptable standard of care. By incorporating these quality indicators into daily practice, the goal is to improve clinical outcomes, quality of life, and decrease healthcare costs.

Table 1: AGA Adult Inflammatory Bowel DiseasePhysician Performance Measure Set.

\section{IBD type}

1. Inflammatory Bowel Disease: type, anatomic location and activity all assessed

Preventative care

1. Corticosteroid Sparing Therapy Prescribed

2.Corticosteroid related iatrogenic injury- bone loss assessment for those receiving corticosteroids

3. Influenza immunization

4. Pneumococcal immunization

5. Tobacco user-screening and cessation intervention

Treatment

1. Testing for latent TB before initiating anti-TNF therapy

2. Assessment of hepatitis B virus before initiating anti-TNF therapy Inpatient Measure

1. Testing for Clostridium difficile

2. Prophylaxis for venous thromboembolism

TB- Tuberculosis, TNF- Tumor Necrosis Factor.

Table 2: Crohn's and Colitis Foundation of America's Quality Indicators for Inflammatory Bowel Disease [8].

\section{Treatment}

1. If a patient is initiating anti-TNF therapy, then TB risk assessment should be documented, and TB skin testing or interferon gamma release assay performed

2. If a patient is initiating therapy with anti-TNF, then risk assessment for hepatitis B virus should be documented
3. If a patient requires at least $10 \mathrm{mg}$ prednisone for $\geq 16$ weeks, then an appropriately dosed steroid-sparing agent should be recommended

4. If a hospitalized patient with severe colitis is not improving on IV steroids within 3 days, then sigmoidoscopy with biopsy should be performed to exclude CMV, and a surgical consultation should be obtained

5. If a patient in whom a fare of IBD is suspected with new or worsening diarrhea, then the patient should undergo C. difficile testing at least once

6. If a patient with IBD is initiating 6MP/AZA, then TPMT testing should be performed before starting therapy

\section{Surveillance}

1. If a patient with UC is found to have confirmed low-grade dysplasia in flat mucosa, then proctocolectomy or repeat surveillance within 6 months should be offered

2. If a patient with extensive UC or CD involving the colon has had their disease for 8-10 years, then surveillance colonoscopy should be performed every $1-3$ years

\section{Health care maintenance}

1. If a patient is on immunosuppressive therapy, then patients should be educated about appropriate vaccination including (1) annual inactivated influenza, (2) pneumococcal vaccination with a 7-year booster, and (3) general avoidance of live virus vaccines

2. If a patient with CD is an active tobacco smoker, then smoking cessation should be recommended and treatment should be offered or a suitable referral provided at least annually TNF - Tumor Necrosis Factor, TB - Tuberculosis, CMV Cytomegalovirus.

IBD - Inflammatory Bowel Disease, 6mp - 6-mercaptopurine.

\section{AZA - Azathioprine, TPMT - Thiopurine Methyltransferase.}

UC - Ulcerative Colitis, CD - Crohn's Disease.

With the development of these Qis, there has been an increase in the research aimed at assessing physician adherence. Studies have revealed high variation in adherence, both in inpatient and clinical settings as well as between IBD vs non-IBD specialists. Tkacz et al. [16] used data collected from a claims database to measure adherence to the quality measurements. They found performance for the AGA ranged from $0.4 \%$ for venous thromboembolism prophylaxis to $66.9 \%$ for Clostridium difficile testing. CCFA outcome measures ranged from $0.6 \%$ for fecal incontinence to $32.9 \%$ for utilization of prednisone. The highest achieved measures for AGA were $C$. difficile testing (66.9\%), appropriate corticosteroid-sparing therapy (51.1\%), and testing for latent tuberculosis before initiating anti-TNF therapy (45\%).16In hospitalized patients with IBD, Nguyen et al demonstrated adherence for VTE prophylaxis and $C$. difficile testing to be $77 \%$ and $82 \%$ respectively.17Similarly in an outpatient setting, Feuerstein et al. performed a chart review of 783 patients between academic, community, and private practice to assess compliance. They found that documented compliance ranged from $16.7 \%$ for pneumococcal immunization to $89 \%$ for tobacco abuse assessment. Only $5.8 \%$ of patients had all core measures documented [18]. In a study comparing IBD 
and non-IBD gastroenterologists, Bilal et al. [19] showed higher adherence for IBD physicians compared to non-IBD $(71.8 \%$ vs. $58.8 \%$ ). Despite the release of the AGA performance measures and the CCFA quality indicators, these studies demonstrate the need for goal directed interventions to improve adherence.

Importantly, institutional and national quality improvement projects can significantly improve adherence to these important quality measurements. For examples, simple vaccination questionnaires prior to a clinic visit increased compliance with influenza vaccination from $54 \%$ to $81 \%$ [19]. Furthermore, informing and educating gastroenterologist toadhere to quality indicators can lead to $16 \%$ improvement in compliance with current guidelines [20].

Through adherence to quality indicators, we expect to improve IBD related clinical outcomes. In a cohort of pediatric patients with IBD, Crandall et al. [21] sought to improve chronic care delivery and outcomes through network-based QI methods. Through improvements in chronic care they demonstrated an increase in the proportion of patients with inactive disease in both patients with Crohn's (55\% to 68\%) and UC (61\% to $72 \%$ ). They also showed a significant increase in the proportion of Crohn's patients not taking prednisone (86\% to 90\%).This data suggests that QI efforts can indeed improve clinical outcomes. Further research in adult patients with IBD is needed to evaluate improvement in outcomes.

In conclusion, there is high variation in the care delivered to our IBD patients. Despite the establishment of quality indicators from both the AGA and CCFA, studies have demonstrated room for improvement in adherence to these quality measures. These measures can have an important impact on the clinical outcomes of our patients with IBD. There are multiple avenues that could be used to implement wide-scale quality improvement including incorporating Qis into our electronic medical records, utilization of care pathways, developing treatment algorithms and many others. We hope that there will continue to be a concerted effort to improve the quality of care delivered to our patients and that this will in turn, improve their health-related outcomes.

\section{Competing Interests and Funding}

The authors do not have any conflict of interests related to the article. The authors do not have any financial interests or affiliations with institutions, organizations, or companies that are mentioned in the manuscript or whose products or services are discussed. The authors do not have any financial interests that might have an impact on the views expressed in the article. Dr. Christophi is partially funded by the NIH grant DK007130.

\section{References}

1. Malik TA (2015) Inflammatory bowel disease: historical perspective, epidemiology, and risk factors. SurgClin North Am 95: 1105-1122.

2. Danese S, Vuitton L, Peyrin-Biroulet L (2015) Biologic agents for IBD: practical insights. Nat Rev Gastroenterol Hepatol12: 537-545.
3. Faubion WA, Loftus EV, Harmsen WS, Zinsmeister AR, Sandborn WJ (2001) The natural history of corticosteroid therapy for inflammatory bowel disease: a population-based study. Gastroenterology 121(2): 255-260.

4. Melmed GY, Siegel CA (2013) Quality Improvement in Inflammatory Bowel Disease. Clin Gastroenterol Hepatl 9: 286-292.

5. Abegunde AT, Muhammad BH, Ali T (2016) Preventive health measures in inflammatory bowel disease. World J Gastroenetrol 22: 7625-7644.

6. Bernstein CN, Blanchard JF, Kliewer E, Wajda A. Cancer risk in patients with inflammatory bowel disease: a population-based study. Cancer 91(4): 854-862.

7. IsHak WW, Pan D, Steiner AJ, Feldman E, Mann A, et al. (2017) PatientReported Outcomes of Quality of Life, Functioning, and GI/Psychiatric Symptom Severity in Patients with Inflammatory Bowel Disease (IBD). Inflamm Bowel disease 23: 798-803.

8. Practice Parameters for the Surgical Treatment of Ulcerative Colitis (revised) (2005) Prepared by The Standards Practice Task Force and The American Society of Colon and Rectal Surgeons. Dis Colon Rectum 48: 1997-2009.

9. Esrailian E, Spiegel BM, Targownik LE, Dubinsky MC, Targan SR, et al. (2007) Differences in the management of Crohn's disease among experts and community providers, based on a national survey of sample case vignettes. Aliment Pharmacol Ther 26: 1005-1018.

10. Selby L, Kane S, Wilson J, Balla P, Riff B, et al. Receipt of preventive health services by IBD patients is significantly lower than by primary care patients. Inflamm Bowel Dis 14(2): 253-258.

11. Reddy SI, Friedman S, Telford JJ, Strate L, Ookubo R, et al. Are patients with inflammatory bowel disease receiving optimal care? Am J Gastroenterol 100(6): 1357-1361.

12. Wagnon JH, Leiman DA, Ayers GD, Schwartz DA (2009) Survey of gastroenterologists' awareness and implementation of AGA guidelines on osteoporosis in inflammatory bowel disease patients: are the guidelines being used and what are the barriers to their use? Inflamm Bowel Dis 15: 1082-1089.

13. Velayos FS, Liu L, Lewis JD, Allison JE, Flowers N, et al. (2010) Prevalence of colorectal cancer surveillance for ulcerative colitis in an integrated health care delivery system. Gastroenterology 139: 1511-1518.

14. American Gastroenterological Association. Adult Inflammatory Bowel Disease Physician Performance Measures Set: American Gastroenterological Association, 2011.

15. Melmed GY, Siegel CA, Spiegel BM, Allen JI, Cima R, et al. Quality indicators for inflammatory bowel disease: Development of process and outcome measures. Inflamm Bowel Dis 19(3): 662-668.

16. Tkacz J, Brady BL, Meyer R, Lofland JH, Ruetsch C, et al. (2012) An assessment of the AGA and CCFA Quality Indicators in a Sample of Patients Diagnosed with Inflammatory Bowel Disease. J Manag Care Spec Pharm 21: 1064-1076

17. Nguyen GC, Murthy SK, Bressler B, Lam MC, Alali A, et al. (2017) Quality of Care and Outcomes Among Hospitalized Inflammatory Bowel Disease Patients: A Multicenter Retrospective Study. Inflamm Bowel Dis 23: 695-701

18. Feuerstein JD, Castillo NE, Siddique SS, Lewandowski JJ, Geissler K, et al. (2016) Poor Documentation of Inflammatory Bowel Disease Quality Measures in Academic, Community, and Private Practice. Clin Gastroenterol Hepatl 14(3): 421-428

19. Parker S, Chambers White L, Spangler C, Rosenblum J, Sweeney S, et al. (2013) A quality improvement project significantly increased the vaccination rate for immunosuppressed patients with IBD. Inflamm Bowel Dis 19(9): 1809-1814. 
20. Greene L, Moreo K (2015) Quality Improvement education to improve performance on ulcerative colitis quality measures and care processes aligned with National Quality Strategy priorities. BMJ QualImprov Report 4: 1-5.
21. Crandall WV, Margolis PA, Kappelman MD, King EC, Pratt JM, et al. (2012) Improved outcomes in a quality improvement collaborative for pediatric inflammatory bowel disease. Pediatrics 129: 1030-1041.

\section{Your next submission with JuniperPublishers will reach you the below assets}

- Quality Editorial service

- Swift Peer Review

- Reprints availability

- E-prints Service

- Manuscript Podcast for convenient understanding

- Global attainment for your research

- Manuscript accessibility in different formats

( Pdf, E-pub, Full Text, audio)

- Unceasing customer service

Track the below URL for one-step submission https://juniperpublishers.com/online-submission.php 